\title{
Construindo espaços de habitar: ações de terapia ocupacional com uma criança \\ em situação de risco social*
}

\section{Building up spaces to live: action of occupational therapy with a child at social risk}

\author{
Ana Claudia Baldani ${ }^{1}$, Eliane Dias de Castro ${ }^{2}$
}

\begin{abstract}
BALDANI A. C.; CASTRO E. D. Construindo espaços de habitar: ações de terapia ocupacional com uma criança em situação de risco social. Rev. Ter. Ocup. Univ. São Paulo, v. 18, n. 1, p. 1-10, jan./abr., 2007.

RESUMO: Este trabalho discute os desdobramentos das ações de terapia ocupacional com uma criança em situação de risco social, possibilitando a abertura de experiências compartilhadas no território da cidade de São Paulo. Estas ações apresentam-se como um potente dispositivo de construção de espaços de habitar o mundo e de aproximação das realidades vividas pela criança e sua família, no embate com a pobreza e a precariedade das condições de vida na Favela do Jaguaré. A necessidade de refletir sobre esta experiência levou-nos a elaborar um projeto de pesquisa no qual a metodologia da pesquisa-ação possibilitou ações de observações diretas das vivências compartilhadas, registros dos encontros, programação conjunta das atividades e estudos teóricos. A composição de um estudo de caso no acompanhamento do sujeitocriança ao longo de vinte meses (abril de 2004 a dezembro de 2005), proporcionou uma reflexão sobre essa prática e suas ressonâncias no desenvolvimento infantil. Aqui atividades lúdicas, artísticas e culturais proporcionaram novas camadas vinculares, uma maior circulação no território da cidade e uma ampliação do repertório sociocultural.
\end{abstract}

DESCRITORES: Terapia ocupacional/tendências. Prática profissional/tendências. Continuidade da assistência ao paciente. Crianças. Terapia ocupacional.

* Pesquisa efetuada a partir do trabalho de campo realizado no projeto de extensão universitária: Ações territoriais em Terapia Ocupacional na interface da Arte e Promoção da Saúde, com bolsa COSEAS-USP.

${ }_{1}$ Bolsista COSEAS e aluna do Curso de Terapia Ocupacional da Faculdade de Medicina da Universidade de São Paulo.

${ }_{2}$ Orientadora do projeto e docente do curso de Terapia Ocupacional da Faculdade de Medicina da Universidade de São Paulo.

Endereço para correspondência: Centro de Docência e Pesquisa em Terapia Ocupacional da FMUSP. Rua Cipotânea, 51. Cidade Universitária. 05508-900. São Paulo-SP. 


\section{INTRODUÇÃO}

$\mathrm{E}$ m 2003, o Laboratório de Estudos e Pesquisa Arte e Corpo em Terapia Ocupacional iniciou o projeto de extensão universitária Terapia Ocupacional e as Ações Territoriais na Interface Arte e Saúde. O projeto consiste no atendimento de crianças em situação de risco social, que participam do programa de atendimento Programa Permanente Composições Artísticas e Terapia Ocupacional (PACTO-Crianças), projeto didático-assistencial do Curso de Terapia Ocupacional da Universidade de São Paulo.

As crianças - com faixa etária entre 4 a 6 anos - foram encaminhadas pela coordenação da Creche Nossa Senhora Aparecida do Jaguaré, bairro da periferia da cidade de São Paulo. A solicitação do atendimento das crianças relacionava-se principalmente às dificuldades de adaptação às rotinas e ao cotidiano institucional, às dificuldades nos relacionamentos interpessoais, principalmente na convivência e no brincar em grupo, momentos nos quais surgiam excessos de agressividade ou apatia que prejudicavam o desenvolvimento das crianças ou o andamento das atividades institucionais, ou ainda, os encaminhamentos estavam relacionados aos conflitos vivenciados nas relações familiares ou à extrema situação de pobreza vivida pela família da criança.

Nos estudos sobre o risco de sobrevivência para crianças de 0 a 6 anos nas cidades brasileiras realizados pela UNICEF, Sposati e Koga (1996) discorrem sobre os principais indicadores deste risco: renda familiar mensal insuficiente (até 1,5 salários mínimos); domicílios com chefes não alfabetizados; e domicílios com água inadequada. De acordo com os dados das autoras, o risco de sobrevivência da população infanto-juvenil do distrito Jaguaré é alto comparado à média dessa população total do município de São Paulo (Tabela 1).

Tabela 1 - Risco de sobrevivência da população infanto-juvenil segundo Sposati e Koga (1996).

\begin{tabular}{l|c|c|c|c|c}
\hline & Com renda insuficiente & Com água inadequada & $\begin{array}{l}\text { Com chefe mulher } \\
\text { analfabeta }\end{array}$ & $\begin{array}{l}\text { Com chefe homem } \\
\text { analfabeto }\end{array}$ & Risco \\
\hline JAGUARÉ & 17,79 & 2,18 & 8,18 & 3,04 & Entre 30 e $40 \%$ \\
MSP & 22,21 & 3,15 & 6,43 & 3,34 & \\
\hline
\end{tabular}

A equipe, composta pela terapeuta ocupacional responsável, pelas estagiárias do Curso de Graduação em Terapia Ocupacional e pela bolsista do projeto, buscou desenvolver com as crianças, um acompanhamento paciente e atento, organizando encontros semanais e neles trabalhando com atividades lúdicas, artísticas e corporais. Neste processo inicial, buscamos oferecer às crianças a oportunidade de desenvolverem seus potenciais criativo, artístico e intelectual, ampliarem suas relações pessoais e suas vivências culturais, enquanto conhecíamos a história de vida e as problemáticas específicas apresentadas por cada uma delas.

Por meio dessas atividades, a equipe almejava facilitar e acompanhar o desenvolvimento neuropsicomotor e afetivo das crianças, fortalecendo-as para suas situações da vida e ativando a resiliência. Para Pinheiro (2004), a resiliência pode ser entendida como a capacidade do sujeito de superar fatores de risco aos quais são expostos, levando ao desenvolvimento de comportamentos adaptativos, segurança, autonomia e criatividade por meio dos mecanismos de proteção e ativação de recursos dos quais a criança poderá dispor na sua rede afetiva e social.
Através de um olhar mais cuidadoso sobre o processo de uma das crianças (M.), foram programados atendimentos individuais, com o objetivo de construir uma experiência vincular de maior aproximação com este sujeitocriança, aproximando-se de seu mundo e contexto, para compreender as singularidades de suas demandas e necessidades reais. Para que este atendimento se efetivasse, foi necessário estruturar materialmente esta possibilidade, concedendo passagens de ônibus para a mãe de M. levá-la à USP, devido às condições financeiras apresentadas pela família. Após um período de aproximadamente seis meses de atendimentos na sala de terapia ocupacional, avaliou-se que para potencializar o desenvolvimento de M., seria necessário ampliar as ações de terapia ocupacional no território, ou seja, nos diversos espaços e equipamentos socioculturais da cidade de São Paulo, próximos à moradia de M. Desta forma, todo o processo de acompanhamento dos atendimentos de terapia ocupacional de M. demandou momentos de ações desenvolvidas em dois planos: num primeiro momento, nos espaços institucionais do Curso de Terapia Ocupacional da USP, o que permitiu uma aproximação 
vincular e um conhecimento maior das necessidades e situações vividas por M. a partir de seus relatos de suas histórias; e num segundo momento, a construção da circulação sociocultural nos recursos do entorno de seu local de vida, auxiliou para que M. conhecesse outros lugares no mundo, a partir dos quais pôde construir experiências, fortalecendo novas formas de expressão e de comunicação que possibilitaram uma expansão e um desenvolvimento em diversas áreas da sua vida.

Para Melo (1997, p. 141),

somos seres em constante movimento. Nossa trajetória, de início - e por vocação - errática, sofre os atritos provocados pelo entorno, com sua vocação conservadora e estática: o que outrora foi potência inovadora tende a enrijecer-se, percorrer circuitos predeterminados, traçando mapas, roteiros. Capturada, a força criadora desgasta-se no atrito. Desacelera. Tende a estancar-se.

\section{PROCEDIMENTOS METODOLÓGICOS}

A necessidade de realizar uma maior reflexão sobre uma determinada experiência de intervenção em terapia ocupacional realizada a partir do acompanhamento e atendimento individual de uma criança que, por algum tempo, compôs o grupo de atendimento PACTO-Crianças, levou-nos a elaborar um projeto de pesquisa no qual a metodologia da pesquisa-ação orientou um conjunto de ações compostas por observações diretas e escuta atenta das necessidades do sujeito da pesquisa e dos sujeitos que compõem seu contexto de vida; vivências compartilhadas entre os sujeitos da pesquisa e o pesquisador; registros das ações desenvolvidas; programação conjunta das atividades; bem como supervisão e discussão do caso atendido.

Esta metodologia foi escolhida por seu importante papel na colaboração e participação de todos os sujeitos envolvidos na pesquisa: pesquisadores e pesquisados atuam na construção de respostas aos problemas e criam diretrizes de ações transformadoras. Para Thiollent (2005, p. 36-40), através dela podemos estabelecer um vínculo entre o raciocínio hipotético e as exigências de comprovação e, por outro lado, levar em conta as argumentações dos pesquisadores e participantes. Além disso a pesquisa-ação é realizada "em estreita associação com uma ação ou com a resolução de um problema coletivo e no qual os pesquisadores e os participantes representativos da situação ou do problema estão envolvidos de modo cooperativo ou participativo" (THIOLLENT, 2005, p. 16).
Nesta perspectiva, pode-se delinear um conjunto de ações que são consideradas etapas da pesquisa, pois o pesquisador encontra-se envolvido com a situação pesquisada, e o conhecimento e a ação possuem uma relação direta com a construção de um campo conceitual, ou seja, o trabalho realizado é permeado pela mediação teórico-conceitual (GIL, 1993, p.123). O problema investigado apresentou a necessidade de estudo dos seguintes eixos teóricos: constituição do vínculo e construção da relação com as pessoas atendidas, desenvolvimento infantil e a importância do brincar, acompanhamento terapêutico, atividades artísticas e culturais, e resiliência nas intervenções em terapia ocupacional. O método propiciou o acompanhamento de forma participativa dos grupos de atendimento do Programa Permanente Composições Artísticas e Terapia Ocupacional, em especial o PACTO-Crianças, os grupos de estudo, reuniões clínicas e supervisões. As etapas de descrição, discussão e análise crítica dos dados colhidos, possibilitaram a apresentação de planos de ação.

Nosso campo investigativo situou-se num território no qual populações diferenciadas, em risco social, enfrentam problemas sociais e existenciais que resultam dos efeitos do funcionamento da sociedade global (desigualdade, desemprego, pobreza, exclusão social, etc.) e das correspondentes relações sociais que são determinantes desses efeitos. A pesquisa-ação valoriza o conhecimento popular resultante destas condições, o que não empobrece a produção científica, pelo contrário, como método de pesquisa social, diferentemente da lógica formal de pesquisa, possibilita uma melhor análise, coleta e elaboração de "sutileza", "funções" e "flutuações" das interações argumentativas, discursivas ou dialógicas" (THIOLLENT, 2005, p. 32).

Neste trabalho, pôde-se coletar, a partir da participação direta nas ações concretas do programa (PACTO), um material que proporcionou a aproximação dos sujeitos envolvidos, de seus anseios e necessidades, de suas vulnerabilidades e potencialidades, engendrando com isso novas diretrizes de ações transformadoras do processo de intervenção, mediadas por um estudo teórico consistente (CASTRO, 2005, p. 11).

Visando complementar o trabalho metodológico, realizou-se a análise documental dos cadernos de registro das atividades realizadas nos atendimentos e a coleta dos relatos orais do grupo familiar do sujeito-criança em questão. Todos esses procedimentos possibilitaram a construção do estudo de caso, que nos forneceu uma visão aprofundada sobre a importância das ações de terapia ocupacional desenvolvidas e analisadas criticamente. 
Entende-se que o estudo de caso é "caracterizado pelo estudo profundo e exaustivo de um ou de poucos objetos, de maneira que permita o seu amplo e detalhado conhecimento" (GIL, 1993, p.58).

A unidade-caso dessa pesquisa compõe-se dos atendimentos de terapia ocupacional de um sujeito-criança ao longo de aproximadamente vinte meses (abril de 2004 a dezembro de 2005) e das experiências vivenciadas por ele durante os atendimentos. Articulou-se a prática terapêutica ocupacional com os eixos teóricos, proporcionando uma maior reflexão sobre essa prática e suas ressonâncias no desenvolvimento de M. e na construção de condições e espaços de habitar o mundo.

\section{DESENVOLVIMENTO}

\section{O sujeito-criança em situação de risco social}

M. é uma criança do sexo feminino com oito anos de idade. Nasceu no município de São Paulo e mora no bairro do Jaguaré, na periferia da zona oeste da cidade. Seus pais são primos e, por este motivo, tem dois irmãos com deficiência física. No total, possui três irmãos mais velhos. Seus pais nasceram no sertão de Pernambuco e vieram para São Paulo em busca de trabalho há dezoito anos. Seu pai não foi alfabetizado, trabalha como pedreiro e conserta máquinas de lavar roupas. Sua mãe não trabalha e apresenta dificuldades em cuidar da casa e dos filhos. A renda familiar mensal, está entre um e cinco salários mínimos, oscilando muito, o que gera grande instabilidade financeira para a família. M. freqüentou a Creche Nossa Senhora Aparecida do Jaguaré até completar sete anos. Segundo a coordenadora desta Creche, no início, suspeitaram de que M. tinha autismo, pela dificuldade que apresentava na interação com outras crianças e no brincar em grupo, porém não foi diagnosticada, nem encaminhada para diagnóstico pelo médico da Unidade Básica de Saúde local. Ingressou na rede de ensino básico, onde apresentou muita dificuldade no aprendizado, não interagia com a maioria das crianças e parecia dispersa, não conseguindo se fixar em uma atividade por muito tempo. M. freqüentou aulas de reforço que aconteciam duas vezes por semana na escola. No entanto, segundo a professora e sua mãe, M. costumava faltar bastante, o que dificultou ainda mais o seu processo de aprendizagem. M freqüentemente fugia de casa, geralmente sendo resgatada pela polícia ou apreendida pelo Conselho Tutelar, o que gerava cenas de violência e ameaças entre as instâncias e os familiares.

\section{O mundo em conta-gotas}

Os contatos iniciais com M. no grupo do PACTOCrianças despertaram a vontade de investigarmos melhor seu desenvolvimento e sua história. M. não parecia apresentar traços autistas e sua curiosidade e interesse em certas brincadeiras sugeria um investimento mais aprofundado. Durante os atendimentos em que se deu o processo de constituição do vínculo com M., novos objetivos se delinearam para a construção de um percurso diferente, de acesso e de experiências deste sujeito-criança aos diversos equipamentos socioculturais (centros culturais, museus, cinemas, parques, praças, entre outros) localizados nos territórios próximos à sua moradia.

O território pode ser considerado como um espaço de possibilidades de se permanecer vivo, reavivando a potência criativa, re-estabelecendo trocas com o ambiente e com outros sujeitos, apesar das situações difíceis que possam ser vivenciadas. As ações territoriais consideram que sujeito e contexto são indissociáveis e cada caso requer estratégicas singulares "de aproximação, de reconhecimento e de compreensão enquanto processo" (OLIVER et al., 2001, p.17).

Nos encontros, avaliou-se que realizar com ela a exploração do território forneceria uma nova experiência para M. habitar o mundo. Habitar é diferente de simplesmente estar em um espaço. Para que o sujeito possa habitar é necessário "um grau de contratualidade elevado em relação à organização material e simbólica dos espaços e dos objetos, à sua divisão afetiva com outros" (SARACENO, 2001, p.114). Habitar significa, então, apropriar-se do espaço, estabelecer relações de pertencimento com ele. E foi essa apropriação que buscamos conquistar nos encontros que aconteceram nos diversos espaços existentes no território.

Neste processo, evidenciou-se outra perspectiva importante: a construção da experiência de apropriar-se do mundo, sentir-se pertencendo a ele. Neste sentido, é necessário em primeiro lugar que o mundo seja apresentado por alguém - alguém que abra na sua própria subjetividade um espaço que dá início e garanta o acontecer humano, e em seguida, é preciso entrar no mundo para que a pessoa sinta-se viva e existente, e isto se dá de maneira singular e pessoal. "Não basta para o acontecer humano o encontro de um mundo pronto com suas estéticas, éticas, códigos e mitos. É preciso, pelo gesto, transformar esse mundo em si mesmo" (SAFRA, 2004, p.35). Barretto (2000, p.48) diz que "o ser humano só se realiza na criatividade, que resulta em um sentimento de existir, e, se ocorre um desenvolvimento, o sujeito pode vir a sentir-se real, o 
que implica em uma apropriação do mundo, tornando-o pessoal". Deste modo, não somente a apropriação como também a possibilidade de realização de "micro" transformações no mundo de forma criativa - produzindo cultura e engendrando histórias - delinearam e contornaram, nos acompanhamentos de M., esse processo de conhecer e habitar o mundo.

Para M., os conflitos familiares, a privação de seus desejos devido à pobreza vivenciada pela família e o fato de permanecer dentro de casa, sem a possibilidade de brincar com outras crianças do bairro e conhecer outros espaços, criavam uma situação de aprisionamento na qual a forma de enfrentamento encontrada era calar-se, esconder-se, retrair-se ou fugir de casa. Para aproximarmonos desta situação, a intervenção terapêutica ocupacional passou a acontecer em contextos reais de vida, utilizandose a técnica do Acompanhamento Terapêutico (AT), que nos possibilitou transitar pelos espaços público e privado (casa de M.), considerados espaços "profundamente marcados pela dimensão do lazer, do descanso e também do conflito" (BARRETTO, 2000, p. 30).

A experiência de passagem para o território aconteceu de forma gradual. A partir dos encontros realizados na própria creche, em seguida nos salões de uma Igreja do bairro (Paróquia São José), e depois nos espaços de atendimento em terapia ocupacional do Curso de Terapia Ocupacional da USP, passamos a conhecer e circular em espaços educativos e culturais dentro do campus da USP, ainda sustentando a necessidade de sua mãe levá-la ao atendimento, e intercalando o acesso a esses equipamentos com os atendimentos realizados na sala de terapia ocupacional. O envolvimento de sua mãe neste processo é decorrente de uma passagem de responsabilização da creche para os atendimentos no serviço de atenção em terapia ocupacional (PACTOCrianças), o que permitiu um novo entendimento de sua situação familiar e a necessidade de envolvimento de sua mãe neste ponto do trabalho. Segundo Safra (2001 apud INFORSATO, 2001, p.20), "do ponto de vista do processo maturacional há uma grande importância na apresentação gradativa da realidade, de modo que a criança possa construir suas formulações".

Após um certo tempo, avaliamos já ser possível - do ponto de vista do processo maturacional e vincular atender ao pedido de M. para irmos ao cinema. Esta saída significou novas negociações: com sua mãe, com M. e com os equipamentos socioculturais. Ao realizarmos esta atividade, foi-nos possível negociar um novo contrato de atendimento, que abriu para que os encontros com $\mathrm{M}$. ocorressem no bairro onde mora, para podermos circular por lugares propostos pela pesquisadora ou escolhidos por M., para instaurarmos novas experiências em seu desenvolvimento. A constituição de uma relação de confiança, com M. e sua família, foi imprescindível para que pudéssemos realizar essas passagens, possibilitando a M. um contato e envolvimento mais intenso com o mundo. M. passou a sentir mais confiança e segurança para aventurar-se em novos lugares e descobrir um novo mundo de possibilidades, onde novos gestos e ações abriam-se para um novo desenvolvimento.

Stern (1991, p.63) diz que o vínculo do apego consiste: na memória e modelos mentais do que acontece entre você e esta outra pessoa: como você se sente com ela. O que ela pode fazer você experimentar que outras não podem. O que você pode se permitir fazer, ou sentir, ou desejar, ou ousar - mas apenas na presença desta pessoa. $O$ que você pode conquistar com seu apoio. Que partes ou visões de você mesmo precisam do ouvido ou olhos da outra pessoa como alimento.

Neste acompanhamento, também foi necessário oferecer a M. atenção, acolhimento e exercer as funções de holding (sustentação) e continência. Segundo Barretto (2000, p. 60), "holding é tudo que, no ambiente, fornecerá a uma pessoa a experiência de uma continuidade, de uma constância tanto física quanto psíquica”, ou seja, a disponibilidade afetiva e corporal do terapeuta, o tempo do atendimento, a qualidade da presença, entre outros aspectos não previamente definidos. Já a continência é a capacidade de um terapeuta ou qualquer outra pessoa de nomear, contextualizar e transformar as experiências de sofrimento e dor de um sujeito.

Na passagem dos atendimentos da sala de terapia ocupacional para o território, por exemplo, a pesquisadora e M. compartilharam uma vivência desta ordem: no caminho para uma oficina de jogos corporais e atividades artísticas, uma chuva muito forte assustou M., que acabou passando mal e vomitando. Paramos em um posto de gasolina para que pudéssemos limpá-la e acalmá-la, um trabalho concreto de acolhimento e sustentação. Isto permitiu sua decisão de não desistirmos do passeio, e ofereceu à M. um tempo para avaliar sua possibilidade de engajamento numa nova experiência, alinhavar sua vontade de conhecer o mundo, sua curiosidade, à sua própria escolha. O trajeto pode então prosseguir numa nova ordem até o local da oficina. A equipe da Oficina deu a ela uma camiseta limpa para que pudesse brincar e participar das atividades de forma mais confortável. M. expressou no ambiente o "vômito" daquilo que foi excessivo para ela, o que a assustava. Apesar de termos iniciado o acompanhamento terapêutico de maneira gradual, evitando causar ansiedades e angústias, não foi 
possível evitar o excesso de estímulos que as novas experiências provocavam. Andar pela cidade, conhecer um novo lugar, atravessar uma chuva forte eram cenas que não constituíam seu repertório existencial. Esses acontecimentos afetaram M. de forma demasiada, entretanto, a confiança e os cuidados dispensados no acolhimento de suas reações expressas, não a impossibilitaram de lançar-se às novidades de uma outra experiência no mundo com os outros.

Para Castro (2005, p.18), o terapeuta, trabalha manejando a intensidade dos estímulos, acertando o pulso na possibilidade do paciente, ajustando o próprio comportamento e suas ações. Ele age em constante feedback, e com isso saberá o que fazer e quando, facilitando os investimentos do paciente no mundo sem forçá-los. Neste processo, o terapeuta inevitavelmente cometerá erros, necessários e potencialmente de grande valor, pois ajudam o paciente no desenvolvimento de seus próprios modos de lidar com uma variedade de experiências e pessoas. Neste sentido, erros não se constituem, necessariamente, como trauma ou tragédia. Eles podem engendrar novas possibilidades de criação de formas existenciais, ou seja, de modos de ser e estar no mundo, e enfrentar as diversas situações da vida.

De forma a dar maior continência aos conteúdos emergidos, buscamos, no encontro posterior, oferecer um espaço para que M. pudesse expressar-se, compartilhar e elaborar de uma outra maneira os acontecimentos ocorridos nesse atendimento. Fomos, então, à Paróquia São José, um local já conhecido por M. e localizado próximo à sua casa, que possui um espaço para brincadeiras e um jardim, o que significou a apresentação de menos estímulos e maior segurança. Além disso, materiais plásticos foram oferecidos e momentos de desenho livre foram propiciados neste novo encontro. Castro (2002, p.4-6) reflete que "facilitar, a um ser humano, a possibilidade de comunicação [é] de grande importância quando a linguagem comum não permite ao sujeito exteriorizar as próprias angústias". Assim, na arte, "encontramos a possibilidade de entendimento de vivências [...] que se apresentam como expressão da condensação das experiências vividas". O fazer artístico, possibilita, portanto, criar novos sentidos e significados para experiências vividas, bem como acessar outras dimensões da experiência.

A partir dessa perspectiva, facilitar a realização de uma atividade artística a M., de desenho e pintura, utilizando diversos materiais, fez com que $\mathrm{M}$. conseguisse expressar o medo que sentiu no momento da chuva. Primeiramente expressou com desenhos, e depois, conversamos sobre seu desenho, e ela falou: Olha! O menino está assustado ... (silêncio) ... acho que ele está com medo da chuva!.
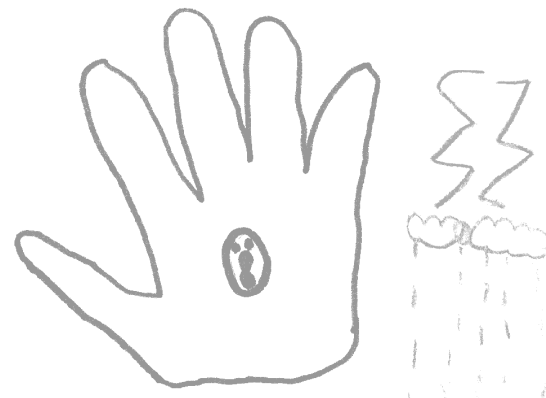

Figura 1 - Desenho de M.

Neste momento, a circulação pelo território mostrouse como um potente dispositivo para o manejo de conteúdos psíquicos e afetivos emergentes em situações reais vivenciadas e compartilhadas. A partir do holding e da continência, e dos espaços de expressão oferecidos no decorrer do AT, M. passou a lidar melhor com suas excitações e ansiedades, querendo realizar outros passeios, o que fortaleceu sua participação nas atividades socioculturais, proporcionando uma maior interação com outras pessoas presentes nos espaços por onde, juntas, pudemos transitar.

\section{Aproximações do contexto e da rede familiar}

Ao acompanhar M. em sua casa, aproximamo-nos da realidade enfrentada pela família no embate com a pobreza, as dificuldades da mãe para cuidar dos filhos e da casa e a fragilidade das relações estabelecidas no núcleo familiar. A partir da convivência e de entrevistas realizadas com cada membro da família, verificamos que os pais sofrem muito pela vida vulnerável e frágil vivida e compartilhada, o que os lançou num jogo de culpas e desentendimentos. No entanto, pareceu-nos evidente a impossibilidade de enfrentamento individual de todo um cenário de privação e desenraizamento decorrente da precarização do trabalho, do desemprego, da pobreza e da desapropriação das próprias vidas que provoca inércia, cenas de violência e exclusão trilhadas pelo casal, que afetam os filhos e a organização familiar.

Para Safra (2002) a condição humana disparada pela precariedade e pelo desenraizamento é uma experiência de sofrimento que ocorre cada vez com maior intensidade no mundo contemporâneo, que multiplica a si própria e é causada por situações anti-humanas que fraturam a cidadania. Situações marcadas por um mundo, nem sempre regido pelo respeito e pela responsabilidade com o humano (SAFRA, 2002, p.38-9). 
Uma passagem que ilustra esse cenário é o comentário do irmão mais velho de M.:

[...] Devido aos dois não se darem muito bem, isso também afeta muito a família. Acho que isso atrapalha! É o principal fator. Precisava de mais auto-respeito. [...]. Diálogo não tem muito e o que tem é só baixaria. [...] É sempre brigando. (Silêncio).

Além disso, falas da mãe demonstram sua dificuldade em lidar com as constantes fugas de M.:

[...] Se o Conselho Tutelar a pegar de novo e achar que ela deve ficar com outra pessoa, tipo, se ela for para boas mãos, aí eu desapareço do mapa. [...] Um filho é tudo na vida da gente, mas morrer por causa de filho não vou não! [...] E lutar por quê? Lutar por uma menina grande que nem ela?.

Por sua vez, o pai comenta: Sou sozinho para tudo... No decorrer dos atendimentos, oferecemos acolhimento a essas questões e buscamos facilitar novas formas de aproximação e relação entre M. e sua família. Uma passagem mostra uma mudança na forma de $\mathrm{M}$. enfrentar alguns conflitos na relação com sua mãe. Por exemplo, M. criou um vaso de flores com argila, tinta, papéis coloridos e massinha para dar à sua mãe de presente. No entanto, sua mãe jogou o vaso no lixo, pois o achou feio! Em um outro momento, M. fez uma boneca de pano - a partir de seu desejo de ter um brinquedo - e sua mãe também a jogou no lixo! M. ficou muito magoada com o gesto da mãe, e falou sobre isto em um dos nossos encontros. Mais tarde, vendo as fotos tiradas em alguns atendimentos, mostrou o vaso e a boneca à mãe e disse: Olha mãe! Está vendo? Você não podia ter jogado fora!.

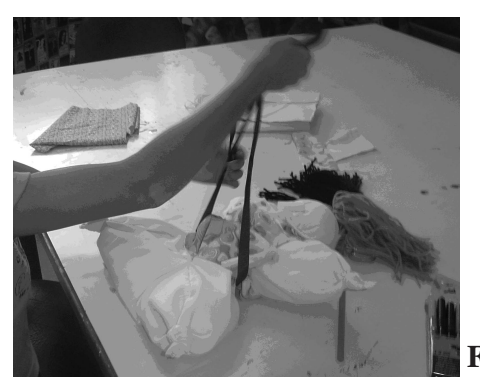

Figura 2 - Boneca de M.

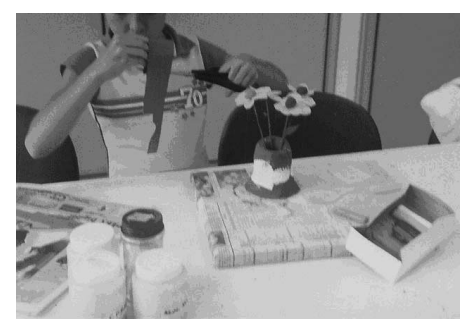

Figura 3 - Vaso de flores de M.
As cenas acima relatadas mostram uma criança fortalecida em seu desenvolvimento a partir de um percurso trilhado conjuntamente nos atendimentos de terapia ocupacional, que embora vivenciando situações de contrariedade, M. pôde encontrar palavras para expressar sua indignação. "A palavra tem a sua eficácia para abertura de possibilidades de ser, se ela tiver a função de gesto, de ação no mundo" (SAFRA, 2002, p.36).

A experiência vincular construída possibilitou uma retomada afetiva de $\mathrm{M}$. em seu desenvolvimento, e demonstrou que esta criança pode lidar criativamente com algumas situações, e conviver com as diferentes formas de experiências que o habitar o mundo compartilhado com outros pode produzir. Desta forma, os atendimentos de terapia ocupacional facilitaram o fortalecimento da resiliência de M., que durante o processo passou a enfrentar as situações com gestos criativos e singulares. "Ser resiliente envolve, também, e principalmente, enfrentar a dor, sofrimento e lançar mão de esforço pessoal" (GARCIA; MAIA, 2004, p.3).

Pudemos, então, reconstruir conjuntamente cenários da vida cotidiana na qual pessoas, coisas e acontecimentos vivem juntos numa constante presença do sensível e dos afetos. Para Safra (2002) a cidadania instaura-se pela possibilidade que tem o ser humano de inserir a sua singularidade por meio de seu gesto. Entretanto, para o autor, é preciso refletir sobre "qual a porosidade do mundo atual para acolher um gesto que possa criar o inédito no campo do mesmo?" (SAFRA, 2002, p.37).

A partir das experiências compartilhadas no território, ficou evidente que o comportamento denominado de "autista" pela creche derivava de uma impossibilidade de expressão e da ausência de um olhar atento e de cuidados singularizados ao seu processo de desenvolvimento. M. também passou a fugir menos de casa e a pedir para seu pai e irmãos levá-la aos lugares conhecidos nos finais de semana, o que configurou experiências de autoagenciamento nas quais a arte e a cultura geraram potências de ação e uma resistente força que passou a abrir passagem para uma participação real, ativa dentro de seu contexto familiar e da construção na existência de uma coletividade.

\section{Encaminhamentos: enfrentando desafios}

Por meio destas ações no território, aproximamos-nos da necessidade de cuidado da família de M. Era preciso oferecer aos sujeitos algum tipo de apoio concreto para o fortalecimento desse núcleo familiar e, conseqüentemente, para a construção de um ambiente favorável ao seu 
desenvolvimento. Saraceno (2001, p.123) diz que "o sofrimento da rede familiar influi na riqueza da rede ampliada e vice-versa. Conseqüentemente, intervenções que melhorem o setting familiar geram também expansões da rede ampliada".

No entanto, cuidar, apoiar ou oferecer suporte às famílias não é tarefa simples, pois nesta modalidade de atenção encontramos resistências, desinformação e desarticulação dos sujeitos com seu entorno sociocultural. Entretanto, avaliamos que o serviço PACTO-Crianças, a partir da estruturação do atendimento das crianças da Creche Nossa Sra. Aparecida, do bairro do Jaguaré, adentrou o território e iniciou um trabalho de construção e articulação de redes para os atendimentos que surgiam como desdobramento das múltiplas e complexas demandas da construção da cidadania das crianças e suas famílias.

Para garantir alguns encaminhamentos foram realizados contatos com a Unidade Básica de Saúde (UBS), com a Paróquia São José (que possui um programa de atendimento de crianças), com a Associação de bairro (SAJA - Sociedade de Amigos do Jaguaré) e com outros equipamentos do entorno sociocultural. Para Saraceno (2001, p. 95-96), estas ações fazem referência ao serviço e não ao tratamento:

Um serviço de alta qualidade deveria ser um "lugar" (constituído de uma multiplicidade de lugares/ oportunidades comunicantes) permeável e dinâmico, onde as oportunidades (ou seja, os recursos e as ocasiões negociáveis) encontram-se continuamente à disposição dos pacientes e dos operadores.

No caso da família de M., encontramos muitas dificuldades para sua mãe buscar acompanhamento psicológico na UBS Jaguaré, apesar de demandar e pedir atenção e acolhimento de seu sofrimento. Deste modo, visualizamos a necessidade de novas formas de agenciamento desta mãe para buscar outras propostas de atenção e participação, outras redes sociais, e poder recuperar certas camadas de experiência que possam reconduzir sua própria existência. De fato, acolher e acompanhar esta demanda exigiu um novo olhar para o território, agora na perspectiva da mãe de M., entretanto, os recursos encontrados e disponibilizados para a sua participação não responderam às suas necessidades e interesses, não foram suficientes para incluí-la num processo de responsabilização com seu próprio sofrimento. Era necessário um vínculo e uma aproximação que o serviço, enfrentando seus limites, não pode acolher.

Nesta situação consideramos que o serviço enfrentou um desafio de articulação com outros recursos que exigiram um percurso de investimentos e descobertas, um cruzamento de lugares, fazeres e outras mães ou mulheres que constituíssem a esta mãe um novo lugar social, com possibilidades de trocas, afetos e significados. Por exemplo, a oferta de participação em uma oficina de tear no âmbito dos serviços da universidade, com outras mães, não se constelou como um lugar de interesse e troca. Após algumas tentativas, a família mudou-se de bairro para aguardar a reforma da casa. Sem dúvida, este cenário abriu para o serviço uma reflexão importante e uma outra necessidade de atuação, mais efetiva para captar as complexidades da vida que envolve esta população.

Numa outra direção, foram também, realizadas tentativas de encaminhamento de M. para outros projetos socioculturais do território. Isto demandou um levantamento minucioso de projetos que acolhessem crianças e adolescentes em situação de vulnerabilidade e risco social e os equipamentos e propostas encontradas apresentavam falta de vagas e grandes filas de espera. Enfim, enfrentamos muitas dificuldades devido à escassez de propostas que pudessem acompanhar sua contínua necessidade de desenvolvimento. O único local que possuía vaga era a Oficina de Dança e Contação de História oferecida pela Associação Morungaba na Biblioteca Clarice Lispector da Lapa. Entretanto, esse encaminhamento de $\mathrm{M}$. não se concretizou devido à dificuldade financeira que impossibilitou o pagamento do ônibus, bem como a indisponibilidade afetiva da mãe para acompanhála neste trajeto.

Um dos contatos realizados neste processo foi com o projeto Aquarela, localizado no distrito Jaguaré, porém, naquele momento o projeto não possuía condições de acolher M. Entretanto, este contato foi muito importante para uma posterior parceria. Atualmente, o projeto Aquarela oferece vagas para algumas crianças que já foram atendidas e estão sendo encaminhadas pelo PACTO-Crianças.

O território do Jaguaré necessita de muitos investimentos e recursos. Necessita também da construção de um percurso de articulação, dos operadores do serviço PACTO-Crianças, dentro da sua capacidade, com lugares que possam ocorrer novos investimentos de sentido, produzindo coletivamente os recursos para o desenvolvimento das crianças e das famílias deste projeto. Desta forma, ampliar a rede de recursos e trabalhar na produção de sentidos aprofundam o senso de pertinência a um projeto que se torna coletivo à medida que se multiplica e agrega transformações às necessidades da população envolvida. Desta forma esta experiência auxiliou-nos numa abertura de visão e uma aprendizagem que instaura novas formas ao próprio projeto. 


\section{CONSIDERAÇÕES FINAIS}

As ações territoriais em Terapia Ocupacional proporcionaram a M. um fortalecimento pessoal e ativação da resiliência, possibilitando-lhe nova condição subjetiva para a criação de outras formas de enfrentamento de suas dificuldades na vida. Nosso longo trabalho foi finalizado ao compreendermos a importância de perceber que esse sujeito-criança está confiante o suficiente para prosseguir caminhando nos territórios da sua vida. Apesar de ser difícil finalizar um vínculo tão intenso e fecundo, é preciso reconhecer que a manutenção dele pode impedir outros processos, também ricos e produtores de VIDA.
As ações teóricas e reflexões produzidas a partir deste acompanhamento permitiram estruturar outras ações do PACTO-Crianças no território da Favela do Jaguaré. Esta experiência fortaleceu outros atendimentos em andamento no serviço e o desenvolvimento de outras crianças que vivem neste mesmo local, bem como ampliou a possibilidade de novas articulações, novas associações e novas formas de cooperação. Fez com que olhássemos de perto situações de precariedade onde a vida humana se desenvolve e conscientizou-nos da necessidade de continuidade de nosso trabalho e da importância da terapia ocupacional nestes contextos.

BALDANI A. C.; CASTRO E. D. Building up spaces to live: action of occupational therapy with a child at social risk. Rev. Ter. Occup. Univ. São Paulo, v. 18, n. 1, p. 1-10, jan./abr., 2007.

\begin{abstract}
This paper discusses the developments of occupational therapy actions taken when dedicating attention to a child at social risk which allowed living shared experiences in the territory of the city of São Paulo. Those actions stood for a potent device to build up spaces to experience the world and to come closer to the reality experienced by the child and her family by facing the poverty and precariousness of the living conditions at Jaguaré slum. The need to reflect on the experience led us to prepare a research project where the action-research methodology allowed observing shared experiences directly, recording meetings, programming together activities and theoretical studies, thus enabling a reflection on the practice and its impacts on children's development and leading to new developments of the very attention device. Playful, artistic and cultural activities enabled new bonding layers, more circulation in the territory of the city and the broadening of the socio-cultural repertoire of all authors involved in the work.
\end{abstract}

KEY WORDS: Occupational therapy/trends. Professional practice/trends. Continuity of patient care. Child.

\title{
REFERÊNCIAS
}

BARRETTO, K. D. Ética e técnica no acompanhamento terapêutico: andanças com Dom Quixote e Sancho Pança. 2a. ed. São Paulo: Unimarco, 2000.

CASTRO, E. D. Habitando os campos da arte e da terapia ocupacional: percursos teóricos e reflexões. Rev. Ter. Ocup. Univ. São Paulo, v. 13, n. 1, p. 1-8, 2002.

CASTRO, E. D. Relatório científico do período 01/08/2003 à 30/07/2004 (FAPESP). São Paulo, jul. 2004.

CASTRO, E. D. Relatório científico do período 01/08/2004 à 30/07/2005 (FAPESP). São Paulo, ago. 2005.

CASTRO, E. D. Inscrições da relação terapeuta-paciente no campo da terapia ocupacional. Rev. Ter. Ocup. Univ. São Paulo, v. 16, n.1, p. 14-21, 2005.

GARCIA, I. S.; MAIA, M. V. M. Resiliência e o pensamento Winnicottiano. p.1-7, 2004. Disponível em: <http:// www.psicologia.com.pt/artigos/ver_artigo.php?codigo $=$ A0190\&area $=\mathrm{d} 5 \&$ subarea $=>$ Acesso em: 20 nov. 2006.

GIL, A. C. Como elaborar projetos de pesquisa. 3a ed. São Paulo: Atlas, 1993.

INFORSATO, E. Aprender o mundo é construir um espaço de habitar. Trabalho apresentado à disciplina "Clínica Winiccottiana" do Programa de Estudos Pós-Graduados em Psicologia Clínica, Pontifícia Universidade Católica de São Paulo, São Paulo, 2001.

MELO, C. R. de. Há devir, há de vir ou o advir da criação no processo terapêutico. In: SaúdeLoucura n ${ }^{\circ} 5$. A clínica como ela é. São Paulo: Hucitec, 1997.

OLIVER, F. C.; GHIRARDI, M. I.; ALMEIDA, M. C.; TISSI, M. C.; AOKI, M. Reabilitação no território: construindo a participação na vida social. Rev. Ter. Ocup. Univ. São Paulo, v. 12, n.1/3, p. 15-22, 2001. 
BAldani, A. C.; CASTRO, E. D. Construindo espaços de habitar. Rev. Ter. Occup. Univ. São Paulo, v. 18, n. 1, p. 1-10, jan./abr., 2007.

PINHEIRO, D. P. N. A resiliência em discussão. Psicol. Estudo, Maringá, v. 9, n. 1, p. 67-75, 2004.

SARACENO, B. Libertando Identidades. Da reabilitação psicossocial à cidadania possível. 2a ed. Belo Horizonte: Te Corá/Instituto Franco Basaglia, 2001.

SPOSATI, A.; KOGA, D. Cartografia Exclusão/inclusão social das crianças e adolescentes na cidade de São Paulo. São Paulo: Educ, 1996.

SAFRA, G. Desenraizamento e exclusão no mundo contempo- râneo In: VAISBERG, T.; AMBRÓSIO, F. Trajetos do sofrimento: desenraizamento e exclusão. São Paulo: IPUSP, 2002.

SAFRA, G. A po-ética da clínica contemporânea. São Paulo: Idéias e Letras, 2004.

STERN, D. N. Diário de um bebê. Porto Alegre: Artes Médicas, 1991.

THIOLLENT, M. Metodologia da pesquisa-ação. 14a ed. São Paulo: Cortez, 2005.

Recebido para publicação: Dez./2006

Aceito para publicação: Jan./2007 